\title{
Assessment of Oral Health Attitude, Knowledge and Behavior among Nursing Students of Karad Taluka
}

\author{
KA Kamala', Janhvi] Rege',,$\underline{\text { S Sankethguddad }}{ }^{3}$, Ajay G Nayak ${ }^{4}$, \\ Abhijeet R Sande $^{5}, \underline{\text { SR Ashwinirani }}{ }^{6}$ \\ ${ }^{1,4}$ Associate Professor, ${ }^{5,6}$ Senior Lecturer, Department of Oral Medicine and Radiology, School of Dental Sciences, KIMSDU, \\ Karad, Pin code - 415110, District- Satara, Maharashtra, India. \\ ${ }^{2}$ Student of Undergraduate Programme, School of Dental Sciences, KIMSDU, Karad, Pin code -415110, District- Satara, \\ Maharashtra, India. \\ ${ }^{3}$ Senior Lecturer, Department of Periodontology, Shivtej Arogya Seva Sanstha's Yogita Dental College and Hospital, Near \\ Naringi River Side, Dapoli Road, Khed, Ratnagiri, Maharashtra, India. \\ DOI: https://doi.org/10.24321/2455.9318.201808
}

Abstract
Introduction: Nurses play an essential role in the society to improve public awareness about general and
oral health. Thus, the aim of this study was to assess knowledge of nursing students and their attitude
towards oral health, and examine their oral health-related behavior among nursing students of Karad
taluka, Maharashtra.
Method: The present study was carried out among 300 nursing students of Karad taluka, Maharashtra. The
questionnaire was self-prepared and consisted of 15 questions related to oral health attitude, knowledge
and behavior, and was distributed to the participants. The data obtained was then statistically analyzed
and the frequency and percentage of the data for all three sections was obtained using statistical package
for social science (SPSS) version 16.
Result: Out of 300 nursing students, 175 (58.33\%) were aware of different techniques used for brushing
teeth and 135 ( $45 \%$ ) students brushed their teeth twice daily. All the students (100\%) preferred using
toothbrush and toothpaste as a cleaning aid.
Conclusion: The current study concluded that most of the studied students had satisfactory basic knowledge
about oral health. The students showed positive attitude towards oral health.
Keywords: Nursing students, Knowledge, Oral health attitude/ behavior

\section{Introduction}

Health has been defined by World Health Organization as a state of complete physical mental and social well-being and not merely absence of disease infirmity. ${ }^{1}$ It has been considered that oral health is essential for general health and is a marker for overall health status. The quality of life can be affected by poor oral health. Medical, dental and paramedical students play an important role in oral health care and its promotion. ${ }^{2}$ Nursing staff plays an important role in health promotion. The knowledge and attitude of nurses is an important factor in shaping and changing

Corresponding Author: Dr. KA Kamala, Department of Oral Medicine and Radiology, School of Dental Sciences, KIMSDU, Karad, Pin code - 415110, District- Satara, Maharashtra, India.

E-mail Id: kamala.kamble@rediffmail.com

Orcid Id: https://orcid.org/0000-0001-7510-2018

How to cite this article: Kamala KA, Rege JJ, Sankethguddad S et al. Assessment of Oral Health Attitude, Knowledge and Behavior among Nursing Students of Karad Taluka. Int J Nurs Midwif Res 2018; 5(1): 32-36. 
community; therefore, it is important that their knowledge about oral health should be good. ${ }^{3}$ Hence the present study was undertaken to evaluate the oral health attitude, knowledge and behavior of nursing students.

\section{Method}

The study was conducted on 300 nursing students of Krishna Institute of Nursing Sciences, Karad and Maharashtra India. Institutional Ethical Committee approval was obtained before commencement of the study. A written informed consent was obtained from all the participants before the start of the study. A questionnaire consisting of 15 questions regarding oral health status, knowledge and behavior was distributed to the participants. An average time of 5 minutes was given to answer the questionnaire. The completed questionnaires were retrieved immediately; data was entered in computer and analyzed statistically.

For the purpose of analysis, items included in the knowledge section of the questionnaire, each positive answer was scored "one" and every negative and do not know answers were scored "zero" and "two" respectively. The answers for the questions based on knowledge regarding plaque and calculus were assigned 1, 2, 3 or 4 where the third option attributed the correct one.

Scores assigned for the behavior section were 1, 2, 3 or 4 based on the number of options for the particular question.

For the attitude section, the variables were graded on a four-point scale. The response was assigned 1, 2, 3 or 4 where 1 was the best response, 4 was the worst. Furthermore, 1 and 2 were combined as the right/positive response while 3 and 4 were combined as wrong/negative response. The frequency and percentage of the data for all three sections was obtained using statistical package for social science (SPSS) version 16.

\section{Results}

The data presented in Table 1 reveals the response to the knowledge section of the questionnaire. Out of 300 nursing students, 175 (58.33\%) were aware of different techniques used for brushing teeth. Majority of the participants, i.e., $59 \%$ were not aware of the different types of floss that are available for oral hygiene maintenance. Only $5.67 \%$ of the participants were acquainted with the meaning of dental plaque, whereas the majority (73.33\%) did not know about it. About $36.67 \%$ of total participants were familiar with calculus being calcified dental plaque while $50 \%$ did not have any knowledge about it. A total of $51 \%$ participants were familiar with the meaning of halitosis. About $14 \%$ were aware about the strengthening property of fluorides as opposed to $64 \%$ who denied it and remaining $21 \%$ who were not sure about it.

The data in Table 2 reveals the response to the behavior section of the questionnaire. Out of 300 nursing students 135 (45\%) of them brush their teeth twice daily. A majority of $83 \%$ participants preferred using toothbrush and toothpaste as a cleaning aid, while $5 \%$ used dental floss and $30 \%$ used a mouthwash. About $28 \%$ respondents changed their toothbrush every 2 months. The data also revealed that $40 \%$ of the participants believed a dental check-up is required only when the need is felt.

Table 3 reveals the data analysis for the attitude section of the questionnaire. Majority of the students had shown a positive attitude toward oral health. Only $1.3 \%$ of participants disagreed that sweets and soft drinks could cause tooth decay. A similar percentage of participants disagreed that it is necessary to have a dental checkup at least once in a year.

\section{Discussion}

Oral diseases are unfavorable to the quality of life and can have an impact on self-confidence, eating ability, and health and social functioning. ${ }^{4}$ Nurses plays an important role in educating and imparting positive oral health knowledge and behavior in the society. And this is possible when they themselves have good oral health-related knowledge and can set an example for their patients in maintaining their good oral health. ${ }^{5}$

The present study consisted of 300 nursing students of 19 to 25 years of age group and all of them were females. The study revealed that about $58 \%$ and $41 \%$ of the respondents had knowledge about different techniques of brushing and various types of dental aids available. This stated that though not satisfactory, a considerable number of the respondents were acquainted with the knowledge related to oral hygiene aids. Plaque is considered as an important etiologic factor in the development of caries and gingivitis. ${ }^{1}$

Only about 5\% nursing students in our study knew what dental plaque means. The present study findings are consistent with a study conducted by Baseer et al. ${ }^{6}$ in 2012 which revealed that less than $28 \%$ health professionals including pharmacists, doctors, nurses, technicians and also medical students were familiar with the meaning of dental plaque. In the same year, Kaira et al. ${ }^{1}$ stated almost $45 \%$ nursing students had good knowledge regarding the role of dental plaque as an etiologic factor in the development of dental caries. About $37 \%$ respondents in the current study were familiar with the basic meaning of calculus. This implies that knowledge regarding the driving factors for periodontal disease can be further improved.

The present data revealed that $51 \%$ of the nursing students understood the term halitosis. This was in contrast with the study conducted among pharmacy students by Rajiah et al. ${ }^{7}$ in 2014 , wherein only $18.9 \%$ of the students gave a positive answer. 
About $14 \%$ respondents were aware of the teethstrengthening property of fluoride according to the present data. Similar findings were revealed in the study conducted by Baseer et al. ${ }^{6}$ Only $1.2 \%$ health professionals had fluoride application on their last visit to the dentist and the results of the study concluded that majority of the health professionals lacked knowledge of fluoride and its benefits in prevention of dental caries.

In the present study, a total $55 \%$ of the nursing students brushed their teeth once daily and $45 \%$ brushed their teeth twice daily. The present study findings were higher compared to Kaira et al. ${ }^{1}$ in which only $28 \%$ of the respondents used to brush once daily. Baseer et al. ${ }^{6}$ reported that $77.9 \%$ health professionals practiced tooth brushing once every day and around 3.9\% practiced it twice daily. The high percentage of brushing once daily in the morning could be due to convenience as it gives feel of freshness.

In our study, all nursing students (100\%) used toothbrush and toothpaste as cleaning agent to clean their teeth. About 5\% and 30\% used dental floss and mouthwash respectively as an adjunct to toothpaste and toothbrush. Same percentage was reported by Bashiru et al. ${ }^{8}$ and Maatouk et al. ${ }^{9}$ in their studies. The percentages were lower in other studies compared to our study. ${ }^{1,3,6}$

Low frequency in the dental visits is a common event observed in developing countries. In the present study, about $40 \%$ of nursing students visited a dental clinic only when it was necessary. Less than $10 \%$ knew the importance of dental visits twice a year in the current study. The fewer visits to dentist could be due to the lack of awareness of importance of oral health, anxiety related to dental treatment and high cost of treatment in developing countries like India. A similar trend was noticed in other studies as well. Bashiru et al. ${ }^{8}$ in his study reported that $33 \%$ of the students had visited the dentist and almost half of the respondents in Kaira et al. ${ }^{1}$ believed to visit a dentist only when they had pain. About $36 \%$ nurses in Baseer et al.' $s^{6}$ study revealed that toothache was the driving factor for visiting the dentist and similar trend was reported by Dagli et al. ${ }^{10}$ in dental students as well. Kumar et al. ${ }^{11}$ and Kawamura et al. ${ }^{12}$ reported $64.9 \%$ and $60 \%$ of the studied population visited dentist only when they had a toothache.

Majority of the students in the present study had shown a positive attitude towards oral health. Only $1.3 \%$ of participants disagreed that sweets and soft drinks could cause tooth decay and that dental checkup was necessary at least once in a year. These results were in consistent with a study conducted by Baseer et al. ${ }^{6}$ where the respondents showed a positive attitude toward dental care. In contrast to this, Mahmoud et al. ${ }^{3}$ revealed that more than half of the nursing students in their study had a negative attitude toward oral health.

\section{Conclusion}

The findings of the present study concluded that most of the nursing students had satisfactory basic knowledge about oral health. The students showed positive attitude towards oral health. Negative oral health attitude could affect students' oral health status and their role in oral health education. As nurses play a pivotal role in the public to improve the awareness about general and oral health, incorporation of the basic topics related to oral hygiene maintenance in the nursing curriculum could help nursing students to have better knowledge.

Table 1.Oral Health Knowledge of Nursing students

\begin{tabular}{|c|c|c|c|}
\hline Question & Options & Number & Percentage \\
\hline $\begin{array}{l}\text { Do you know the different } \\
\text { techniques for brushing teeth }\end{array}$ & $\begin{array}{l}\text { Yes } \\
\text { No }\end{array}$ & $\begin{array}{l}175 \\
125\end{array}$ & $\begin{array}{l}58.33 \\
41.60\end{array}$ \\
\hline $\begin{array}{l}\text { Do you know there are different } \\
\text { types of floss available }\end{array}$ & $\begin{array}{l}\text { Yes } \\
\text { No }\end{array}$ & $\begin{array}{l}123 \\
177\end{array}$ & $\begin{array}{l}41 \\
59\end{array}$ \\
\hline What is dental plaque & $\begin{array}{c}\text { Debris on teeth } \\
\text { Staining of teeth } \\
\text { Tenacious thin film on teeth } \\
\text { I don't know }\end{array}$ & $\begin{array}{c}56 \\
7 \\
17 \\
220\end{array}$ & $\begin{array}{c}18.67 \\
2.33 \\
5.67 \\
73.33\end{array}$ \\
\hline What is calculus & $\begin{array}{l}\text { Soft debris on teeth } \\
\text { Staining of teeth } \\
\text { Calcified dental plaque } \\
\text { I don't know }\end{array}$ & $\begin{array}{c}11 \\
29 \\
110 \\
150\end{array}$ & $\begin{array}{c}3.67 \\
9.67 \\
36.67 \\
50\end{array}$ \\
\hline Do you know what is halitosis & $\begin{array}{l}\text { Yes } \\
\text { No }\end{array}$ & $\begin{array}{l}153 \\
147\end{array}$ & $\begin{array}{l}51 \\
49\end{array}$ \\
\hline $\begin{array}{c}\text { Using fluoride strengthens the } \\
\text { teeth }\end{array}$ & $\begin{array}{c}\text { Yes } \\
\text { No } \\
\text { I don't know }\end{array}$ & $\begin{array}{c}43 \\
192 \\
65\end{array}$ & $\begin{array}{c}14.33 \\
64 \\
21.67\end{array}$ \\
\hline
\end{tabular}


Table 2.Oral Health Behavior of Nursing students

\begin{tabular}{|c|c|c|c|}
\hline Question & Options & Number & Percentage \\
\hline $\begin{array}{l}\text { How often do you brush } \\
\text { your teeth }\end{array}$ & $\begin{array}{l}\text { Once daily } \\
\text { Twice daily } \\
\text { Thrice daily } \\
\text { Not at all }\end{array}$ & $\begin{array}{c}165 \\
135 \\
- \\
-\end{array}$ & $\begin{array}{l}55 \\
45 \\
- \\
-\end{array}$ \\
\hline $\begin{array}{l}\text { What do you use for } \\
\text { cleaning your teeth }\end{array}$ & $\begin{array}{c}\text { Brush + Toothpaste } \\
\text { Dental floss } \\
\text { Mouth wash } \\
\text { Tooth picks } \\
\text { Others }\end{array}$ & $\begin{array}{c}300 \\
15 \\
30 \\
5 \\
-\end{array}$ & $\begin{array}{c}100 \\
5 \\
10 \\
1.67 \\
-\end{array}$ \\
\hline $\begin{array}{c}\text { When do you brush your } \\
\text { teeth }\end{array}$ & $\begin{array}{c}\text { Only in the morning } \\
\text { Only before going to bed } \\
\text { Both the times }\end{array}$ & $\begin{array}{c}165 \\
- \\
135\end{array}$ & $\begin{array}{c}55 \\
- \\
45\end{array}$ \\
\hline $\begin{array}{l}\text { How frequently do you } \\
\text { change your toothbrush }\end{array}$ & $\begin{array}{l}1 \text { month } \\
2 \text { months }\end{array}$ & $\begin{array}{c}215 \\
85\end{array}$ & $\begin{array}{l}71.67 \\
28.33\end{array}$ \\
\hline $\begin{array}{l}\text { How often do you go for } \\
\text { dental checkup }\end{array}$ & $\begin{array}{c}\text { Once in a year } \\
2 \text { times in a year } \\
\text { Only when necessary } \\
\text { Not at all }\end{array}$ & $\begin{array}{c}149 \\
17 \\
121 \\
13\end{array}$ & $\begin{array}{c}49.67 \\
5.67 \\
40.33 \\
4.33\end{array}$ \\
\hline
\end{tabular}

Table 3.Attitude of Nursing Students towards Dentistry

\begin{tabular}{|c|c|c|c|}
\hline Question & Options & Number & Percentage \\
\hline $\begin{array}{c}\text { Do you agree it is necessary to } \\
\text { brush in the morning and at } \\
\text { night to keep the teeth healthy }\end{array}$ & Strongly agree & 192 & $64 \%$ \\
& Agree & 108 & - \\
& Disagree & - & - \\
\hline Do you agree it is necessary & Strongly disagree & - & $50.33 \%$ \\
to rinse the mouth with water & Agree & 151 & $49.67 \%$ \\
after every meal to remove the & Disagree & - & - \\
food debris & Strongly disagree & - & - \\
\hline Do you agree sweets and soft & Strongly agree & 171 & $57 \%$ \\
drinks can cause tooth decay & Agree & 125 & $1.67 \%$ \\
& Disagree & - & - \\
\hline Do you agree it is necessary to & Strongly disagree & - & $37.33 \%$ \\
have a dental checkup at least & Strongly agree & 112 & $61.33 \%$ \\
once in a year & Agree & 184 & $1.33 \%$ \\
& Disagree & 4 & - \\
\hline
\end{tabular}

\section{Conflict of interest: None}

\section{References}

1. Kaira LS, Shrivasthava V, Giri P et al. Oral health related knowledge attitude and practice among nursing students Rohilkhand Medical College and Hospital A questionnaire study. J Orofac Res 2012; 2: 20-23.

2. Katekar G, Kamala KA, Sankethguddad S et al. Oral health attitude, knowledge and practices of dental students- a questionnaire study. Int J Curr Res 2017; 9: 51280-83.

3. Mahmoud SR. Oral health knowledge, attitude and behavior of nursing school students in Assiut city. AAMJ 2013; 11: 27-50.

4. Davies RM, Davies GM, Ellwood RP. Prevention. Part 4: Tooth brushing: What advice should be given to patients. Br Dent J 2003; 195: 135-41.

5. Suttagul K, Dolo P, Toh-Adam R et al. A study on dental health behavior of nursing students in Western University. BJMMR 2017; 19: 1-11.

6. Baseer MA, Alenazy MS, Alasqah M et al. Oral health knowledge, attitude and practices among health professionals in King Fahad Medical City, Riyadh. Dent Res J 2012; 9: 386-92.

7. Rajiah K, Ving CJ. An assessment of pharmacy students' 
knowledge, attitude, and practice toward oral health: An exploratory study. J Int Soc Prevent Communit Dent 2014; 4: S56-62.

8. Bashiru BO, Omotola OE. Oral health knowledge, attitude and behavior of medial, pharmacy and nursing students at the University of port Harcourt, Nigeria. $J$ oral Res Rev 2016; 8: 66-71.

9. Maatouk F, Maatouk W, Ghedira $\mathrm{H}$ et al. Effect of 5 years of dental studies on the oral health of Tunisian dental student. East Mediterr Health J 2006; 12: 62531.

10. Dagli RJ, Tadakamadla S, Dhanni C et al. Self-reported dental health attitude and behavior of dental students in India. J Oral Sci 2008; 50: 267-72.
11. Kumar S, Busaly IA, Tadakamadla J et al. Attitudes of dental and pharmacy students to oral health behavior at Jazan University, Kingdom of Saudi Arabia. Arch Orofac Sci 2012; 7: 9-13.

12. Kawamura M, Ikeda-Nakaoka Y, Sasahara H. An assessment of oral self-care level among Japanese dental hygiene students and general nursing students using the Hiroshima University-Dental Behavioural Inventory (HU-DBI): Surveys in 1990/1999. Eur J Dent Educ 2000; 4: 82-88.

Date of Submission: 2018-04-04 Date of Acceptance: 2018-04-10 